\title{
PERAN ACCOUNT OFFICER DALAM MENEKAN KREDIT BERMASALAH (Studi pada BPR di Kab .Grobogan )
}

\author{
THE ROLE OF ACCOUNT OFFICER IN PRESSING PROBLEM CREDIT \\ (Study on BPR in Kab. Grobogan) \\ ${ }^{1}$ Endang Rusdianti, ${ }^{2}$ Paulus Wardoyo, ${ }^{3}$ Ani Setyarini \\ 1,2,3 Pasca sarjana,Magister Manajemen,Universitas Semarang \\ 1endang_rusdianti@yahoo.com, ${ }^{2}$ Adyalk@gmail.com, ${ }^{3}$ ririn_gt@yahoo.co.id
}

\begin{abstract}
The research objective is to analyze the role of Account Officers in suppressing non-performing loans from the Rural Banks of Kabupaten Grobongan. The analysis relates to whether the role of the account officer influences the business of the banking sector in granting credit so that it can reduce problem loans. The proxy role of the account officer is the ability to analyze credit and supervision activities by considering customer development as a moderating variable. The method used is the MRA, SPSS 22. The data type is primary data obtained by questionnaire method on the variables of credit analysis, supervision, customer guidance and problem loans. The respondents were 70 Accounts from the BPR of Kabupaten Grobogan The results show that credit analysis and supervision have an effect on bad credit. Moderating variables are used to overcome bad credit, namely customer coaching as an effort to increase / weaken the relationship of credit analysis and supervision of bad credit. The result of coaching on credit analysis does not act as moderation but acts as a predictor. In relation to supervision, coaching acts as a quasi moderation and results are negative, which means that coaching actually weakens the influence of supervision.
\end{abstract}

Keywords: Account Officer, credit analysis, supervision, coaching, problem loans

\section{PENDAHULUAN}

Perbankan mempunyai kegiatan yang mempertemukan pihak yang membutuhkan dana dan pihak yang mempunyai kelebihan dana. Melalui kegiatan pinjaman, bank berusaha memenuhi kebutuhan masyarakat bagi kelancaran usahanya, sedangkan dengan kegiatan penyimpanan dana, bank berusaha menawarkan kepada masyarakat akan keamanan dananya dengan jasa lain yang akan diperoleh
(Julius, 2009): Banyaknya kredit bermasalah yang terjadi bisa disebabkan dari berbagai pihak, tetapi setidaknya pencegahan awal dari pihak lembaga adalah melakukan analisis kredit dengan teliti. Disini peran Account Officer sangatlah penting karena kegiatan analisis kredit dan semua keputusan pemberian kredit adalah kewenangan dari seorang Account Officer.

Edratna menyatakan bahwa Account Officer adalah orang yang 
bertugas sejak mencari nasabah yang layak sesuai kriteria peraturan bank, menilai, mengevaluasi, mengusulkan besarnya kredit yang diberikan. Untuk mendapatkan seorang AO yang berkualitas, diperlukan pendidikan yang memadai dan jam terbang, agar bisa mengenali usaha yang layak dibiayai. Sejak deregulasi perbankan diluncurkan pemerintah, terutama sejak pakto (paket kebijakan oktober) 27, pasar perbankan Indonesia bergeser dari seller's market menjadi buyer s'market yang ditandai dengan pertumbuhan kapsitas perbankan yang jauh lebih cepat dari pertumbuhan pasar. Dalam kondisi seperti itu, maka pandangan marketing (marketing point of view) diperlukan untuk memenangkan persaingan. Cara kerja yang tradisional (mengharapkan nasabah mendatangi bank) harus ditinggalkan bila bank tidak ingin kalah dalam perbankan. Di Indonesia= sistem Account Officer mulai digunakan sejak deregulasi 1 Juni 1983, sebagai upaya untuk meraih pasar yang lebih luas dan untuk meningkatkan efisiensi guna meraih profitabilitas yang lebih baik ditengah persaingan yang tajam. (http:// wwwmickeyblue.co.id/2009/ 05 /perananaccount-officer , diakses 27 Oktober 2015 ).

Sistem Account Officer menarik para bankir, karena keunggulan sistem tersebut yang terletak pada peranannya yang terbesar dalam menghubungkan bank dengan nasabahnya, bertugas melayani semua keperluan nasabah yang berkaitan dengan perkreditan, pemasaran dan pembiayaan,di bank tersebut secara utuh Account Officer yang profesional memberikan pelayanan yang diperlukan nasabah. Account Officer dituntut memiliki keahlian dan keterampilan, penguasaan pengetahuan yang bersifat teoritis. mampu menganalisis, aspek ekonomi keuangan, manajemen, hukum, dan teknis, serta memiliki wawasan yang luas mengenai prinsip-prinsip perklreditan. Pada dasarnya peran dan fungsi seorang Account Officer adalah: a. Mengelola Account b. Mengelola produk c. Mengelola kredit d. Mengelola penjualan e. Mengelola profitability

\section{Rasio kredit bermasalah BPR} dari tahun ke tahun semakin memburuk, di tahun 2015 sebesar 6,58\% dan di tahun 2016 menjadi $6,95 \%$ (Bisnis.com,2017). Untuk Kabupaten Grobogan terlihat bahwa NPL sebesar 6,72\% (tahun 2016). Yang berarti masih diatas persyaratan kredit bermasalah yaitu 5\%. Pengawasan dan Pembinaan terhadap nasabah harus sudah dilakukan sebelum kredit menjadi tidak lancar.Beberapa penelitian menemukan 
bahwa BPR yang memberikan insentif kepada AO atas kredit yang tertagih cenderung menurunkan kredit bernasalah, kunjungan rutin AO kepada debitur untuk memantau penggunaan kredit dapat memperkecil rasio NPL. . Komunikasi yang baik antara BPR dan debitur yang dilakukan oleh AO berdampak pada rasio NPL yang lebih kecil.Kunjungan rutin AO dalam memantau penggunaan kredit hanya dapat dilakukan dengan baik jika AO tersebut termotivasi. BPR yang memberikan insentif kepada $\mathrm{AO}$ atas kredit yang tertagih dapat memotivasi AO untuk melaksanakan tugas pembinaan dan penagihan yang lebih baik sehingga rasio NPL dapat ditekan untuk semakin kecil.

\section{Berdasarkan permasalahan} tersebut diatas maka rumusan masalahnya adalah bagaimanakah peran dari account officer kaitannya dengan menekan kredit bermasalah. Dan apakah proses pembinaan nasabah bisa menjadi variabel yang memoderating antara kemampuan analisis kredit dan pengawasan terhadap kredit bermasalah .

Tujuan penelitian untuk menganalisis kemampuan account officer dalam menekan kredit bermasalah melalui analisis kredit serta melalui pengawasan. Selain itu juga untuk menganalisis apakah pembinaan nasabah bisa menjadi variabel moderasi dalam usaha menekan kredit bermasalah.

Kredit ialah penyediaan uang atau tagihan yang dapat dipersamakan dengan itu, berdasarkan persetujuan dan kepercayaan atas kesepakatan pinjam meminjam antara bank dengan pihak lain yang mewajibkan pihak peminjam untuk melunasi hutangnya setelah jangka waktu tertentu dengan jumlah bunga, imbalan atau pembagian hasil keuntungan (UU No. 10 Tahun 1998 Tentang Perbankan).

Surbakti (2012) untuk dapat melaksanakan kegiatan perkreditan secara sehat telah dikenal adanya prinsip 5C Kelima prinsip yang klasik ini meliputi :a.Character . peminjam mempunyai moral, watak ataupun sifatsifat pribadi yang positif dan kooperatif, punya integritas, jujur punya rasa tanggung jawab $b$. Capacity yaitu suatu penilaian kepada calon debitur mengenai kemampuan melunasi kewajiban-kewajibannya melalui $c$. Capital Yaitu jumlah dana/modal sendiri yang dimiliki d.Collateral yaitu barang-barang jaminan sebagai alat pengamanan e. Condition of economy Yang dimaksud dengan condition of economy yaitu situasi dan kondisi politik, social, ekonomi, budaya 
Dinamika Sosial Budaya, Vol 20, No. 2, Desember 2018, pp 182-192 p-ISSN: 1410-9859\& e-ISSN: 2580-8524

http://journals.usm.ac.id/index.php/jdsb

dan lain-lain

Kedit Bermasalah adalah kredit yang tidak dibayar sesuai dengan jadwal yang telah ditentukan. Selain itu, kredit macet adalah kredit yang tidak lancar dan telah sampai pada jatuh temponya belum dapat juga diselesaikan oleh nasabah bersangkutan (Kuncoro 2002). Kredit bermasalah menurut (Surbakti,2012) adalah piutang tak tertagih, Siamat (2004) kredit macet merupakan kredit yang mengalami kesulitan pelunasan akibat adanya faktorfaktor kesengajaan atau karena kondisi diluar kemampuan debitur.

BPR (Bank Perkreditan Rakyat) adalah lembaga keuangan bank yang menerima simpanan hanya dalam bentuk deposito berjangka, tabungan, dan/atau bentuk lainnya yang dipersamakan dengan itu dan menyalurkan dana melayani golongan pengusaha mikro, kecil dan menengah. BPR sudah ada sejak jaman sebelum kemerdekaan yang dikenal dengan sebutan Lumbung Desa, Bank Desa, Bank Tani dan Bank Dagang Desa atau Bank Pasar. BPR merupakan lembaga perbankan resmi yang diatur berdasarkan Undang-Undang No. 7 tahun 1992 tentang Perbankan dan sebagaimana telah diubah dengan Undang-undang No. 10 tahun 1998. Dalam undang-undang tersebut secara jelas disebutkan bahwa ada dua jenis bank yaitu Bank Umum dan BPR

Mcleod (2004:) menyatakan bahwa, sistem pengawasan kredit adalah Sistem berisikan prosedur yang harus dilalui dalam melaksanakan suatu kegiatan untuk melindungi hak perusahaan dari penyelewengan yang dapat merugikan perusahaan. Pengawasan kredit ini merupakan upaya untuk menjaga dan mengamankan kredit yang bersifat preventif.

Pembinaan adalah upaya pencairan sampai dengan pelunasanyang dilakukan kaitannya dengan penilaian perkembangan usaha nasabah, penggunaan kreditnya dan perlindungan untuk kepentingan bank yang dilakukan secara off site (secara administrasi ) maupun secara on site (secara langsung di lapangan) .

Manfaat penelitian ini diharapkan bisa berkontribusi bagi BPR untuk bisa meningkatkan peran dari account officer dalam menekan kredit bermasalah. serta menambah wawasan keilmuan i perilaku dari account officer dan nasabah kaitannya dengan usaha pengamanan pemberian kredit.

\section{METODE}

Jenis penelitian adalah penelitian asosiatif kasual (causal assosiative research). digunakan metode penelitian kuantitatif, yaitu metode 
Dinamika Sosial Budaya, Vol 20, No. 2, Desember 2018, pp 182-192 p-ISSN: 1410-9859\& e-ISSN: 2580-8524

http://journals.usm.ac.id/index.php/jdsb

penelitian yang berlandaskan pada filsafat positivism. Variabel-variabel dalam penelitian ini Variabel Analisis Kredit dan Pengawasan sebagai variabel independen. Analisis kredit diukur dengan kemampuan AO di dalam menganalisis nasabah dan Pengawasan diukur dengan kemampuan AO dalam melaksanakan pengawasan terhadap pencairan dan pengembalian kredit. Variabel Pembinaan sebagai variabel moderating.Variabel pembinaan diukur dengan kemampuan dari AO untuk melakukan pembinaan terhadap nasabah. Variabel dependen dalam penelitian ini adalah kredit bermasalah. Kredit bermasalah diukur dengan analisis penyebab macetnya kredit

Data yang digunakan dalam penelitian ini adalah data primer berupa pernyataan Account Officer yang di intervalkan melalui pertanyaan dalam kuesioner untuk masing-masing variabel penelitian, diukur dengan menggunakan skala 1-10, yaitu suatu skala yang digunakan untuk mengukur sikap, pendapat, persepsi seseorang atau sekelompok orang tentang fenomena sosial. Jawaban dari responden yang bersifat kualitatif dikuantitatifkan, dimana jawaban diberi skor dengan menggunakan 10 point, yaitu :

Nilai 1 = Sangat Tidak setuju (STS)
Nilai $10=$ Sangat Setuju (SS)

Populasi dari penelitian ini adalah Account Officer BPR Kabupaten Grobogan sejumlah 70 orang. Semuanya dijadikan responden (dilaksanakan dengan metode sensus).Metode pengumpulan data yang digunakan yaitu Metode Observasi Tidak Langsung dan Metode kuesioner yang disebarkan bersifat tertutup dan terbuka untuk bisa menggali lebih banyak permasalahan yang terkait dengan variabel penelitian. Statistik deskriptif digunakan untuk mendeskripsikan variabel penelitian dengan menggunakan tabel distribusi frekuensi yang menunjukan angka mean, kisaran skor dan standar devisi.

Tahapan dalam metode ini adalah : Uji Instrumen melalui Uji validitas (uji kesahihan) dikatakan valid jika pertanyaan pada kuesioner mampu mengungkapkan sesuatu yang akan diukur oleh kuesioner (Ghozali, 2014., Danang Sunyoto, Validitas dan Reabilitas (Yogyakarta: Nuha Medika, 2012),

Hasil penelitian menunjukkan bahwa semua nilai corrected item correlation berada diatas $+/-2$, sehingga dapat disimpulkan bahwa semua indikator valid. . Uji reliabilitas . Kriteria dikatakan reliable apabila nilai nilai Cronbach's Alpha > 0,7 (Ghozali, 2014). Uji reliabilitas dilakukan terhadap Analisis kredit, Pengawasan, Pembinaan 
dan Kredit bermasalah. Berdasarkan tabel dapat diketahui bahwa masingmasing variabel memiliki nilai alpha melebihi nilai standarisasi yaitu sebesar 0,7 .

Uji Asumsi Klasik . Uji normalitas dilakukan dengan uji Kolmogorov Smirnov, adalah uji beda antara data yang diuji normalitasnya dengan data normal baku. Seperti pada uji beda biasa, jika signifikansi di bawah 0,05 berarti terdapat perbedaan yang signifikan. Jika signifikansi di atas 0,05 maka tidak terjadi perbedaan yang signifikan. Data dinyatakan berdistribusi normal Uji multikolinearitas adanya hubungan linear antar variabel independen dalam model regresi. Alat yang digunakan untuk menguji gangguan multikolinearitas adalah dengan Variance Inflation Factor (VIF), dan tolerance. Hasil penelitian menunjukkan bahwa data bebas dari permasalahan multikolinearitas karena tolerance semuanya $>0.01$ dan $\mathrm{VIF}<10$ Uji heteroskedostisitas digunakan untuk melihat apakah terdapat ketidaksamaan varian dari residual dari semua pengamatan pada model regresi. Syarat yang harus dipenuhi adalah tidak adanya gejala heteroskedastisitas. Metode pengujian yang digunakan adalah $\mathrm{Uji}$ Glesjer,.

Dari hasil pengujian heteroskedastisitas menunjukkan bahwa tingkat sign $\alpha>$ dari 0.05 berarti bebas dari penyakit heteroskedastisitas

Menurut Ghozali (2011) pengujian model regresi dengan variabel moderating dapat dilakukan dengan 3 alternatif uji yaitu : (1) Uji interaksi, (2) uji nilai selisih mutlak, dan (3) uji residual. Penelitian ini dilakukan menggunakan uji interaksi untuk menguji pengaruh variabel moderasi terhadap hubungan antara variabel independen dan variable/terikat. Uji Regresi Linier Berganda, Moderate Regression Analysis (MRA) dan uji t. Tahapan Pengelolaan Data dengan variabel Moderator adalah: Uji Regresi Berganda X1 dan X2 terhadap Y, Uji variabel X3 apakah Pure Moderator, Quasi Moderator, atau Bukan Moderator, Pengamatan beta positif atau negatif dari interaksi variabel, Pengujian menggunakan variabel pemoderasi adalah untuk melihat apakah variable moderasi memperkuat atau memperlemah hubungan variabel bebas dan variabel terikat. Uji interaksi atau sering disebut dengan Moderated Regression Analysis (MRA) merupakan aplikasi khusus regresi berganda linear dimana dalam persamaan regresinya mengandung unsur interaksi (perkalian dua atau lebih variabel independen) (Ghozali, 2011). Variabel perkalian antara analisis kredit (X2), 
Dinamika Sosial Budaya, Vol 20, No. 2, Desember 2018, pp 182-192 p-ISSN: 1410-9859\& e-ISSN: 2580-8524

http://journals.usm.ac.id/index.php/jdsb

pengawasan kredit (X1) dengan

Pembinaan nasabah (X3) yang merupakan variabel moderating karena menggambarkan pengaruh moderating variabel pembinaan (X3) terhadap hubungan analisis kredit (X2) dan pengawasan (X1) dengan kredit bermasalah (Y). Gambar model regresi penelitian ini seperti yang nampak pada

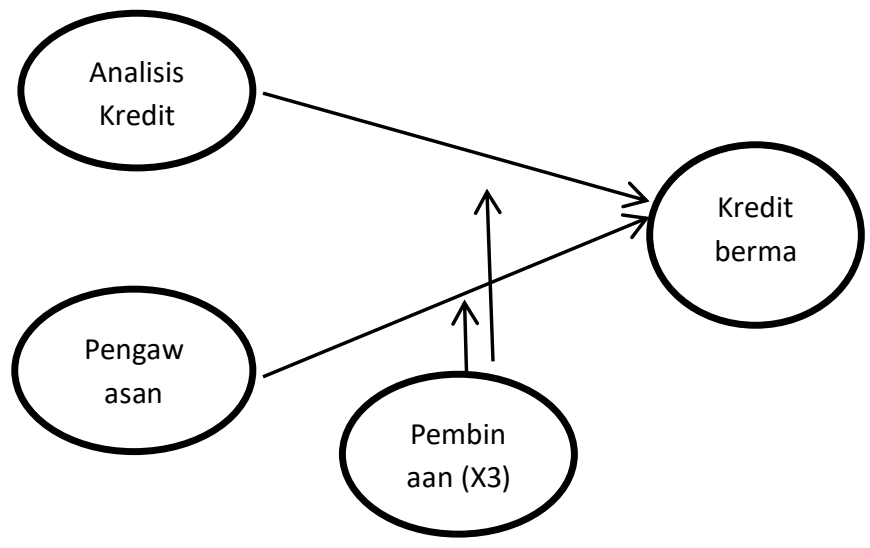
gambar dibawah

Gambar 1. Model regresi penelitian

\section{HASIL DAN PEMBAHASAN}

Tabel 1. Hasil Regresi Berganda

\begin{tabular}{|c|c|c|c|c|c|c|}
\hline \multirow{2}{*}{\multicolumn{2}{|c|}{ Model }} & \multicolumn{2}{|c|}{ Unstandardized Coefficients } & \multirow{2}{*}{$\begin{array}{c}\begin{array}{c}\text { Standardized } \\
\text { Coefficients }\end{array} \\
\text { Beta }\end{array}$} & \multirow[t]{2}{*}{$\mathrm{t}$} & \multirow[t]{2}{*}{ Sig. } \\
\hline & & $\mathrm{B}$ & Std. Error & & & \\
\hline \multirow{3}{*}{1} & (Constant) & 14,161 & 3,622 & & 3,910 &, 000 \\
\hline & $\mathrm{X} 1$ & ,374 & , 198 & ,290 & 1,888 & ,063 \\
\hline & $\mathrm{X} 2$ & 459 & ,255 & 276 & 1,799 &, 076 \\
\hline
\end{tabular}

a. Dependent Variable: $\mathrm{Y}$

Persamaan regresi : $\mathrm{Y}=0,290 \mathrm{X} 1+0,276 \mathrm{X} 2$

Tingkat signifikansi menunjukkan

X1 sig 0,063 (signifikan di level 10\%) dan X2 sig 0.076 (signifikan di level 10\%

) Berdasarkan beberapa pendapat, untuk penelitian sosial masih dimungkinkan tingkat signifikansi $10 \%$. Hasil penelitian menunjukkan bahwa variabel analisis kredit dan pengawasan kredit a.Variabel analisis kredit terhadap kredit bermasalah dengan pembinaan nasabah sebagai moderasi berpengaruh secara signifikan dan arahnya positif terhadap kredit bermasalah.. Moderated Regression Analysis dilakukan untuk menguji pengaruh interaksi antara Analisis kredit, pengawasan, dan pembinaan nasabah terhadap kredit bermasalah. 
Dinamika Sosial Budaya, Vol 20, No. 2, Desember 2018, pp 182-192

p-ISSN: 1410-9859\& e-ISSN: 2580-8524

http://journals.usm.ac.id/index.php/jdsb

Tabel 2. Regresi X1,X3 terhadap Y

\begin{tabular}{|c|c|c|c|c|c|c|}
\hline \multirow{2}{*}{\multicolumn{2}{|c|}{ Model }} & \multicolumn{2}{|c|}{ Unstandardized Coefficients } & \multirow{2}{*}{$\begin{array}{c}\begin{array}{c}\text { Standardized } \\
\text { Coefficients }\end{array} \\
\text { Beta }\end{array}$} & \multirow[t]{2}{*}{$\mathrm{t}$} & \multirow[t]{2}{*}{ Sig. } \\
\hline & & $\mathrm{B}$ & Std. Error & & & \\
\hline \multirow{3}{*}{1} & (Constant) & 4,184 & 4,008 & & 1,044 & ,300 \\
\hline & $\mathrm{X} 1$ & ,293 & , 141 & ,228 & 2,079 & ,041 \\
\hline & X3 & ,945 & 207 & ,501 & 4,576 & ,000 \\
\hline
\end{tabular}

a. Dependent Variable: Y

b. Predictors: (Constant), X3, X1

Variabel analisis kredit (sign .041) dan

kedua variabel tersebut berpengaruh pembinaan nasabah (sgn .000) berarti

positif terhadap kredit bermasalah

Tabel 3. MRA X1,X3,X1X3 terhadap Y

\begin{tabular}{|rl|r|r|r|r|r|}
\hline \multicolumn{2}{|c|}{ Model } & \multicolumn{2}{|c|}{ Unstandardized Coefficients } & \multicolumn{1}{c|}{$\begin{array}{l}\text { Standardized } \\
\text { Coefficients }\end{array}$} & \multicolumn{1}{c|}{ Sig. } \\
\cline { 3 - 5 } & \multicolumn{1}{|c|}{ B } & Std. Error & \multicolumn{1}{c|}{ Beta } & \\
\hline \multirow{4}{*}{1} & (Constant) & $-21,652$ & 17,128 & & $-1,264$ &, 211 \\
& X1 & 1,548 &, 821 & 1,201 & 1,885 &, 064 \\
& X3 & 2,082 &, 761 & 1,103 & 2,735 &, 008 \\
& X1X3 &,- 054 &, 035 & $-1,398$ & $-1,551$ &, 126 \\
\hline
\end{tabular}

a. Dependent Variable: $\mathrm{Y}$

b. Predictors: (Constant), X1X3, X3, X1

Varibel pembinaan nasabah sebagai berperan sebagai prediktor moderasi yaitu variabel moderasi menunjukkan tidak signifikan (sign .126) dan bertanda negatif, berarti pembinaan nasabah hanya variabel yang hanya berperan sebagai b.Variabel Pengawasan terhadap kredit variabel prediktor (independen) dalam model hubungan yang dibentuk. bermasalah dengan varabel pembinaan nasabah sebagai moderasi

Tabel 4. Regresi X2,X3 terhadap Y

\begin{tabular}{|c|c|c|c|c|c|c|}
\hline \multirow{2}{*}{\multicolumn{2}{|c|}{ Model }} & \multicolumn{2}{|c|}{ Unstandardized Coefficients } & \multirow{2}{*}{$\begin{array}{c}\text { Standardized } \\
\text { Coefficients } \\
\text { Beta }\end{array}$} & \multirow[t]{2}{*}{$\mathrm{t}$} & \multirow[t]{2}{*}{ Sig. } \\
\hline & & B & Std. Error & & & \\
\hline \multirow{3}{*}{1} & (Constant) & 2,717 & 4,165 & & ,652 &, 516 \\
\hline & $\mathrm{X} 2$ &, 382 &, 180 & ,230 & 2,122 & ,038 \\
\hline & $\mathrm{X} 3$ & .949 & 204 & .503 & 4,644 & ,000 \\
\hline
\end{tabular}

a. Dependent Variable: Y

b. Predictors: (Constant), X3, X2 
Dinamika Sosial Budaya, Vol 20, No. 2, Desember 2018, pp 182-192 p-ISSN: 1410-9859\& e-ISSN: 2580-8524

http://journals.usm.ac.id/index.php/jdsb

Variabel pengawasan (sign .038) dan signifikan terhadap kredit bermasalah. pembinaan nasabah (sgn .000) berarti kedua variabel tersebut berpengaruh

Tabel 5. MRA X2,X3,X2X3 terhadap Y

\begin{tabular}{|rl|r|r|r|r|r|}
\hline Model & \multicolumn{2}{|c|}{ Unstandardized Coefficients } & \multicolumn{1}{c|}{$\begin{array}{c}\text { Standardized } \\
\text { Coefficients }\end{array}$} & \multirow{2}{*}{ Sig. } \\
\cline { 3 - 5 } & & \multicolumn{1}{|c|}{ B } & Std. Error & \multicolumn{1}{|c|}{ Beta } & \\
\hline \multirow{2}{*}{ (Constant) } & $-35,645$ & 19,788 & & $-1,801$ &, 076 \\
& X2 & 2,309 &, 988 & 1,389 & 2,336 &, 023 \\
& X3 & 2,611 &, 862 & 1,383 & 3,028 &, 004 \\
& X2X3 &,- 082 &, 042 & $-1,791$ & $-1,981$ &, 052 \\
\hline
\end{tabular}

a. Dependent Variable: Y

b. Predictors: (Constant), X2X3, X3, X2

Varibel pembinaan nasabah sebagai variabel moderasi signifikan (sign .052) dan bertanda negatif, berarti pembinaan nasabah berperan sebagai quasi moderasi yaitu variabel yang memoderasi hubungan antara variabel pengawasan dan kredit bermasalah yang sekaligus menjadi variabel prediktor. Tanda negatif menunjukkan variabel pembinaan nasabah memperlemah pengaruh pengawasan terhadap kredit macet.Hasil perhitungan MRA untuk signifikansi dalam uji t terhadap kredit bermasalah adalah sebagai berikut :
1. $\mathrm{X} 1 \mathrm{X} 3$ uji $\mathrm{t}-1,551$ dengan sign .126 berarti moderasi berpengaruh negatif tetapi tidak signifikan artinya hipotesis null tidak sanggup di tolak (variabel moderasi tidak berpengaruh terhadap kredit macet).2.X2X3 uji t - 1,981 dengan sign ,052 berarti moderasi berpengaruh negatif dan signifikan artinya hipotesis null di tolak (variabel moderasi berpengaruh dan melemahkan pengaruh terhadap kredit macet).

Tabel 6. Koefisien Determinasi

\begin{tabular}{|c|c|c|}
\hline o & Keterangan & Adjusted R Square \\
\hline 1 & Regresi awal & .257 \\
\hline 2 & MRA X1X3 & .418 \\
\hline 3 & MRA X2X3 & .433 \\
\hline
\end{tabular}

Berdasarkan tabel di atas menunjukkan bahwa besarnya nilai koefisien determinasi meningkat dengan adanya variabel moderasi yaitu bahwa variabel kredit bermasalah mampu dijelaskan oleh variabel analis 
kredit sebesar 25,7\% menjadi 41,8\% dan sisanya5,2\% dijelaskan oleh variabel di luar penelitian ini. Sedangkan variabel kredit bermasalah mampu dijelaskan oleh variabel pengawasan sebesar $25,7 \%$ menjadi $43,3 \%$ dan sisanya dijelaskan oleh variabel diluar penelitian ini.

\section{KESIMPULAN}

Variabel analisis kredit berpengaruh positif dan signifikan terhadap kredit bermasalah. Analisis kredit yang dilakukan dengan baik akan mengurangi resiko tidak terbayarnya pinjaman. Variabel pengawasan berpengaruh positif dan signifikan terhadap kredit bermasalah. Pengawasan yang dilakukan baik secara preventif dan represif sehingga mengurangi resiko kredit bermasalah. Variabel pembinaan berpengaruh positif terhadap kredit bermasalah. Tetapi sebagai variabel pembinaan bertindak sebagai variabel prediktor artinya variabel pembinaan tidak bisa bertindak sebagai variabel moderating tetapi bisa bertindak sebagai variabel independen terhadap kredit bermasalah. V ariabel pembinaan berpengaruh positif terhadap kredit bermasalah. Tetapi variabel pembinaaan bisa bertindak sebagai quasi moderasi dengan arah negatif. Artinya pembinaan memperlemah hubungan pengawasan terhadap kredit macet.

Analisis kredit dan pengawasan berpengaruh terhadap usaha $\mathrm{AO}$ dalam menekan kredit bermasalah artinya semakin ketat dalam melakukan analisis dan pengawasan berarti semakin baik dalam usahanya menekan kredit bermasalah. Dalam analisis kredit ini yang dilakukan oleh $\mathrm{AO}$ adalah berkaitan dengan pertimbangan 5C (Character, Capital, Capacity, Collateral, Condition of Economy) dan melakukan prosedur analisis 6A(analisis aspek yuridis, analisis aspek dasar dan pemasaran, analisis aspek teknis, analisis aspek manajemen, analisis aspek keuangan, analisis aspek sosial ekonomi) Analisis moderasi variabel pembinaan kaitannya dengan analisis kredit berpengaruh positif terhadap kredit bermasalah tetapi sebagai variabel moderasi menunjukkan tidak sign, berarti pembinaan justru berperan sebagai variabel prediktor terhadap kredit bermasalah.Variabel pembinaan kaitannya dengan pengawasan berpengaruh positif terhadap kredit bermasalah tetapi sebagai variabel moderasi bertindak sebagai quasi moderasi karena sifatnya melemahkan Sistem monitoring yang komprehensif yang dilaksanakan secara disiplin dan konsisten perlu dilakukan sehingga dapat 
memantau secara dini perkembangan dan gejala nasabah yang tidak baik. AO diwajibkan melakukan kunjungan rutin ke nasabah secara periodek dan wajib membuat callreport yang kemudian diarsipkan ke dalam file nasabah. Pengawasan yang baik dilakukan oleh AO akan dapat menurunkan tingkat kredit bermasalah karena sifat pengawasan bisa dilakukan dengan cara langsung yaitu langsung mengunjungi debitur dan tidak langsung melalui catatan laporan keuangan/usaha debitur atau melalui informasi pihak ketiga. Tujuannya adalah untuk mendeteksi gejala ketidakberesan usaha agar kredit menjadi tidak bermasalah

\section{DAFTAR PUSTAKA}

Bramantyo,2007, Penelitian GTZ dan Bank Indonesia

Danang Sunyoto ,2011,Yogyakarta: Nuha Medika

Edratna, 2011, AO, NPL retrieved april 30,2011 from http://edratna,wordpress.com/201 1/10/18/aonpl/tentang/judul_AO_NPL Ghozali,Imam, 2011, aplikasi analisis multivariate, Semarang, BPFE Undip http: // wwwmickeyblue. .co.id /2009/05/peranan-accountofficerdalam-kur.html, diakses 27 Oktober 2015

Ifah Latifah 2008, Peranan AO dalam menekan pembiayaan bermasalah

Jusuf, Jopie. Panduan dasar untuk Account Officer, (Yoguakarta: Akademi Manajemen Perusahaan YKPN,1997),

Kuncoro, .mudrajad, 2002, manajemen perbankan, teori dan aplikasi, FE, UGM

Sanusi ,2011, Anwar, Metode Penelitian Bisnis, Salemba Empat, Jakarta

Sugiyono,2006, metode penelitian bisnis, Bandung, Alfabeta

Siamat, Dahlan. 2004. Manajemen Lembaga Keuangan. Jakarta: PT. Gramedia

Surbakti, Elpina Susanti,2012, Analisis Penyelesaian Kredit Bermasalah Pada PT.BRI (Persero), Tbk, Unit Medan Labuhan, Skripsi: Universitas HKBP Nommensen, Medan, 2012.

Undang-Undang No. 7 tahun 1992 tentang Perbankan dan sebagaimana telah diubah dengan Undang-undang No. 10 tahun 1998 UU No. 10 Tahun 1998 Tentang Perbankan. 